\title{
The quality of antenatal care in rural Tanzania: what is behind the number of visits?
}

\author{
Angelo S Nyamtema ${ }^{1 *}$, Alise Bartsch-de Jong ${ }^{2}$, David P Urassa ${ }^{3}$, Jaap P Hagen ${ }^{4}$ and Jos van Roosmalen ${ }^{2,4}$
}

\begin{abstract}
Background: Antenatal care (ANC) provides an important opportunity for pregnant women with a wide range of interventions and is considered as an important basic component of reproductive health care.

Methods: In 2008, severe maternal morbidity audit was established at Saint Francis Designated District Hospital (SFDDH), in Kilombero district in Tanzania, to ascertain substandard care and implement interventions. In addition, a cross-sectional descriptive study was carried out in 11 health facilities within the district to assess the quality of ANC and underlying factors in a broader view.

Results: Of 363 severe maternal morbidities audited, only 263 (72\%) ANC cards were identified. Additionally, 121 cards (with 299 ANC visits) from 11 facilities were also reviewed. Hemoglobin and urine albumin were assessed in $22 \%-37 \%$ and blood pressure in $69 \%-87 \%$ of all visits. Fifty two (20\%) severe maternal morbidities were attributed to substandard ANC, of these 39 had severe anemia and eclampsia combined. Substandard ANC was mainly attributed to shortage of staff, equipment and consumables. There was no significant relationship between assessment of essential parameters at first ANC visit and total number of visits made (Spearman correlation coefficient, $r=0.09 ; p=0.13$ ). Several interventions were implemented and others were proposed to those in control of the health system.

Conclusions: This article reflects a worrisome state of substandard ANC in rural Tanzania resulting from inadequate human workforce and material resources for maternal health, and its adverse impacts on maternal wellbeing. These results suggest urgent response from those in control of the health system to invest more resources to avert the situation in order to enhance maternal health in this country.
\end{abstract}

\section{Background}

Antenatal care (ANC) provides an important opportunity for pregnant women with a wide range of interventions including education, counseling, screening, treatment, monitoring and promoting the well-being of the mother and fetus [1-3]. Evidence of the effectiveness of ANC interventions exists around the world when sought early in pregnancy and quality care continues until delivery $[2,4,5]$.

Tanzania has adopted the World Health Organization (WHO) recommendation of a minimum of four goaloriented ANC visits during a woman's pregnancy [6,7]. At minimum blood pressure (BP), hemoglobin $(\mathrm{Hb})$ estimation, weight gain, testing of urine for albumin and

\footnotetext{
* Correspondence: nyamtema_angelo@yahoo.co.uk

'Department of Obstetrics and Gynecology, Saint Francis Referral Hospital, Ifakara, Tanzania

Full list of author information is available at the end of the article
}

sugar, fundal height, fetal lie and movements/ or heart rate assessments are recommended in every ANC visit. Tests for syphilis, HIV status, blood group and Rhesus factor as well as maternal height measurement are recommended at least once. Other ANC services include preventive strategies for tetanus, malaria, anemia and mother to child HIV-transmission, education (birth preparedness and complications readiness, care of newborn, family planning as well as treatment of detected ill health.

Although the majority (94\%) of pregnant women in Tanzania attend ANC at least once, the quality of care has been of great concern [8]. Maternal mortality and maternal morbidity audit (4 M study) was established at Saint Francis Designated District Hospital (SFDDH) in 2008 aimed to improve service delivery and utilization, and recommend relevant policies [9]. A second phase was carried out in December 2010 to assess in a broader 
view the quality of antenatal care services and underlying factors in Kilombero district, Tanzania.

\section{Methods}

\section{Study area}

Kilombero is a rural district located in the south-western part of Tanzania. In 2002 it had a total population of 321,661 people with annual population growth rate of $2.6 \%$ [10]. Antenatal care services are offered in 44 health facilities including a 372-bed SFDDH (including maternity waiting home services), a 120 bed capacity Illovo (parastatal) hospital, 4 public health centers and 38 private and public dispensaries scattered around the district.

\section{Sample size and sampling technique}

The first phase of the $4 \mathrm{M}$ study involved audit of all mothers with severe maternal morbidities and mortalities at SFDDH. The inclusion criteria and the auditing process have been described elsewhere [11]. The second phase of the study involved stratified sampling technique to obtain 11 health facilities out of 44 health institutions in Kilombero district (25\% representation fulfilling WHO recommendation to cover at least $25-30 \%$ of the health facilities in the area when assessing quality of care [12]. These included 2 hospitals, 2 health centers and 7 dispensaries. All clients who came for antenatal clinics on the day of study were included in this study.

\section{Data collection}

Data of the first phase (severe maternal morbidities audit) was collected and entered in Access database. The second phase of the study was a cross-sectional descriptive study which was intended at assessing the quality of antenatal care in the district. Four tools were used in this phase i.e. two checklists and two semi-structured questionnaires. The first checklist was used at the exit of clients to assess ANC cards for completeness of parameters, routinely assessed during ANC visits. These parameters included weight, maternal height, blood pressure, hemoglobin estimation, glucose in urine, albumin in urine, VDRL test, HIV test, blood group and rhesus status, provision of hematenics (iron and folate) and mebendazole. The presence of risk factor(s) which are routinely recommended on the ANC card were also reviewed. These include history of Caesarean section, age below 20 years, primigravida at age above 34 years, grand multiparous (more than 5 previous deliveries) and stature less than $150 \mathrm{~cm}$. The ANC guideline in Tanzania recommends that women with these risk factors deliver in a hospital with comprehensive emergency obstetric services. An exit interview of ANC clients was carried out using a semi-structured questionnaire to assess whether they were advised on delivery and if they were satisfied with the quality of service they received. Another checklist was used to assess the staffing level, availability of essential equipment, medical supplies and drugs necessary for provision of ANC services in each health facility. A second semi-structured questionnaire was also used to interview in-charges of health facilities about the factors that affected the quality ANC service.

Ethical clearance for the study was obtained from SFDDH Research and Publication Committee. Permission to conduct the cross-sectional descriptive study was obtained from the office of the District Medical Officer and the respective in-charges of the selected health facilities. Verbal informed consent was obtained from all interviewees i.e. in-charge of health facilities and clients whose ANC cards were reviewed. Confidentiality, privacy and cultural values were also taken into consideration.

\section{Data analysis}

Quantitative data was analyzed using SPSS software. The principal summary measures were proportions of essential parameters assessed during ANC visits and the corresponding 95\% confidence intervals $(95 \% \mathrm{CI}$ ). The relationship between assessment of essential parameters at first visit and the total number of visits made was determined using correlation analysis. Essential parameters (BP, $\mathrm{Hb}$ and albumin in urine) measured at first ANC visit were scored i.e., each parameter was given one point when it appeared that it was assessed, making a maximum score of 3 . The authors hypothesized that by assessing these parameters, involving her blood sample, urine sample and physique, a woman would feel adequately assessed and hence motivated to make more visits. Although blood and urine samples are also used for other tests, it was logically assumed that these tests may not have changed in the way how a woman felt to be assessed during the first visit. Mothers with complications of abortion, ectopic pregnancies and those who started ANC visits after 20 weeks of gestation were excluded from this correlation analysis because they were not expected to make a recommended minimum of four visits.

Qualitative data was analyzed using a method described by Graneheim and Lundman [13]. Analysis included thorough reading of the transcribed text to identify meaning units. The meaning units were then condensed, abstracted, coded and then categorized according to similarities and differences in content.

\section{Results}

\section{Findings from the audit phase}

Of all 363 women with severe maternal morbidities admitted at SFDDH from October 2008 to July 2010, ANC cards were found in only 263 (72\%). Of the women 
without ANC cards some left them at home, others had not started ANC visits and the rest were misplaced within the hospital. Out of the total 754 ANC visits made by these 263 women with antenatal cards, BP, Hb and albumin in urine were assessed in only $69 \%, 25 \%$ and $22 \%$ respectively. The audit team attributed 52 (20\%) of the 263 mothers with ANC cards to substandard antenatal care. Of these 39 (75\%) were mothers presenting with severe anemia in pregnancy and eclampsia combined who had attended ANC clinics regularly but the respective parameters were never checked. During audit it was not clear whether the substandard assessment of these parameters was due to poor supply of essential ANC equipment, drugs and consumables or because of poor performance of care providers. Correlation analysis indicated that there was no significant relationship between the assessment of essential parameters at first visit and the total number of ANC visits made by 63 women who qualified for analysis (Spearman correlation coefficient, $\mathrm{r}=0.09 ; \mathrm{p}=0.13$ ).

\section{Findings from cross sectional descriptive study}

Antenatal cards belonging to 121 pregnant women attending in 11 antenatal clinics in Kilombero district were reviewed with an average of 11 (ranging from 4 35) cards from each facility. Of these cards, 95 (79\%) belonged to women with primary education, only one belonged to a client with post secondary education. Of all women $107(88 \%)$ were peasants, 7 (6\%) petty businesswomen and 7 (6\%) were either employee in the public or nongovernmental institutions. More than a quarter $(26 \%)$ of these women were primigravida, $51 \%$ were gravida $2-4$ and $92 \%$ were married.

Out of the total 299 ANC visits made hemoglobin estimation, glucose and albumin in urine were assessed in almost one third $(27 \%-37 \%)$ of the visits (Table 1$)$. Although majority $(83 \%)$ of mothers had made at least 2

Table 1 Proportions of check ups of parameters and prophylactic drugs recommended for every ANC visit

\begin{tabular}{|c|c|c|c|c|c|}
\hline \multirow[t]{2}{*}{ Parameters } & \multicolumn{2}{|c|}{$\begin{array}{l}\text { Hospitals* } \\
\text { (ANC visits = 127) }\end{array}$} & \multicolumn{2}{|c|}{$\begin{array}{l}\text { First Level } \\
\text { Health Facilities } \\
\text { (ANC visits }=172 \text { ) }\end{array}$} & \multirow[t]{2}{*}{$\begin{array}{l}\text { Total\% } \\
\text { (visits = 299) }\end{array}$} \\
\hline & $\%$ & $95 \% \mathrm{Cl}$ & $\%$ & $95 \% \mathrm{Cl}$ & \\
\hline Weight & 89 & $84-94$ & 74 & $67-81$ & 80 \\
\hline Blood pressure & 98 & $96-99$ & 78 & $72-84$ & 87 \\
\hline $\mathrm{Hb}$ estimation & 45 & $34-54$ & 32 & $25-39$ & 37 \\
\hline Albumin in urine & 47 & $38-56$ & 20 & $14-26$ & 32 \\
\hline Glucose in urine & 42 & $33-51$ & 15 & $10-20$ & 27 \\
\hline Iron tablets & 77 & $70-84$ & 45 & $38-54$ & 59 \\
\hline Folate tablets & 71 & $63-79$ & 45 & $38-54$ & 56 \\
\hline
\end{tabular}

NB: *Only data from the second phase of the study (cross sectional descriptive study) is included here; First Level Health Facilities = health centers \& dispensaries.
ANC visits, blood group and rhesus status, and VDRL were tested in only $7 \%$ and $48 \%$ respectively (Table 2 ). With exception of $\mathrm{Hb}$ estimation, HIV test, blood grouping and rhesus status, and provision of mebendazole, the rest of the routine services recommended for ANC in Tanzania were statistically significantly more checked / provided in the hospitals than in lower health facilities.

Of all women $63(52 \%)$ had at least one risk factor. Of women with risk factors 27 (42\%) were under 20 years of age, 12 (19\%) had short stature less than $150 \mathrm{~cm}$ and 11 were grand multiparous. Delivery advice was provided to only 40 (33\%) women attending ANC on the day of study. The most frequent delivery advice (93\%) given to women with risk factors was hospital delivery, when to go and use of maternity waiting home. On the other hand, 25 (40\%) women with risk factors reported that they did not receive any advice on the delivery plan. On the contrary, 93 (77\%) women reported that they were satisfied with the ANC services they received in these facilities. This number included women who had a risk factor but never received any delivery advice.

\section{Factors affecting ANC services delivery}

BP machines, stethoscopes, weighing scales, HIV test kits, folic acid, mebendazole and SP drugs for IPT were available in nearly all $(91 \%-100 \%)$ facilities during the period of this study. Hb estimation machines were available in less than two thirds (64\%) of the health facilities. The respondents (in charge of health facilities) reported that some essential equipment like BP machines were of poor quality leading to short durability contributing to the shortage. Glucostik and albustik kits were available only in $18 \%$ and $27 \%$ of all health facilities respectively. $\mathrm{Hb}$ estimation machines, Glucostik and albustik kits were completely unavailable in these facilities for up to 12 months before the study. Generally, there was severe shortage of staff for antenatal care in all dispensaries and health centers. Shortage of qualified staff and irregular

Table 2 Proportions of check ups of parameters and prophylactic drugs recommended at least once during ANC period

\begin{tabular}{|c|c|c|c|c|c|}
\hline \multirow[t]{2}{*}{ Parameters } & \multicolumn{2}{|c|}{$\begin{array}{l}\text { Hospitals } \\
\text { Clients }=43\end{array}$} & \multicolumn{2}{|c|}{$\begin{array}{l}\text { First Level Health } \\
\text { Facilities Clients }=78\end{array}$} & \multirow{2}{*}{$\begin{array}{l}\text { Total clients } \\
\mathrm{n}=121 \\
\%\end{array}$} \\
\hline & $\%$ & $95 \% \mathrm{Cl}$ & $\%$ & $95 \% \mathrm{Cl}$ & \\
\hline Height & 93 & $88-99$ & 56 & $45-67$ & 69 \\
\hline HIV Test & 91 & $82-99$ & 74 & $64-84$ & 80 \\
\hline VDRL Test & 67 & $53-81$ & 37 & $26-48$ & 48 \\
\hline $\begin{array}{l}\text { Blood group \& } \\
\text { Rhesus factor }\end{array}$ & 5 & $1-12$ & 9 & $3-15$ & 7 \\
\hline Mebendazole & 77 & $64-90$ & 54 & $43-65$ & 62 \\
\hline
\end{tabular}

NB: Only data from the second phase of the study (cross sectional descriptive study) is included; First Level Health Facilities = dispensaries and health centers. 
supply of essential equipment, drugs and consumables were considered by $91 \%$ and $64 \%$ of the respondents respectively as the major underlying factors for substandard ANC (Table 3).

\section{Interventions}

A list of strategic interventions for quality ANC improvement in the district were proposed and implemented as a result of audit. These included regular feedback to ANC providers, recommendations were shared with the regional and district heath authorities to improve staffing levels, essential supplies and equipment, and supportive supervision for quality antenatal care. The Medical Store Department (MSD), the central government supplier of medical equipment, drugs and consumables, was also contacted through a series of meetings and advised to improve the ordering and supply mechanisms to enhance quality and availability of essential supplies.

\section{Discussion}

This article reveals a state of poor assessment of essential parameters for antenatal care in rural Tanzania despite adoption of goal-oriented ANC with a limited number of visits. Despite the complexity of interacting factors, antenatal education, screening and treatment of common causes of maternal and perinatal mortalities and morbidities such as pre-eclampsia and anemia constitute a body of benefits of ANC interventions [5,14,15]. The effectiveness of such ANC interventions has been linked to its quality, access and coverage [15]. The fact that comparable findings indicating substandard provision of vital ANC services have been repeatedly reported in rural sub-Saharan Africa since the last decade, suggest dormant health systems, an alarming state of inadequate utilization of research findings in these countries and the urgent need for improvement [16-20].

Table 3 Factors affecting quality antenatal care in Kilombero district

\begin{tabular}{ll}
\hline Factors affecting quality antenatal care & $\begin{array}{l}\text { Proportions of } \\
\text { respondents } \mathbf{n = 1 1}\end{array}$ \\
\hline Shortage of qualified staff & $91 \%$ \\
\hline Irregular supply of ANC equipment and drugs & $64 \%$ \\
\hline Regular but inadequate supplies & $45 \%$ \\
\hline $\begin{array}{l}\text { Cultural factors and ignorance } \\
\text { among pregnant women }\end{array}$ & $36 \%$ \\
\hline Lack of staff motivation & $27 \%$ \\
\hline Poor infrastructure for ANC & $18 \%$ \\
\hline $\begin{array}{l}\text { Long distance to the health facility } \\
\text { with ANC services }\end{array}$ & $9 \%$ \\
\hline
\end{tabular}

The fact that $20 \%$ of severe maternal morbidities were attributed to substandard ANC suggests a remarkable proportion of adverse pregnancy outcome that could be reduced by improving this program. These findings suggest also that women from rural Tanzania belong to a group that would need quality ANC the most in the world [14]. The high prevalence of ANC attendance in sub-Saharan Africa [8,21] and positive attitude about antenatal care despite its poor quality [22], offer an important opportunity for quality maternal care improvement. These findings pose a great challenge to those in control of health systems in sub-Saharan Africa to invest more resources in antenatal care in order to accelerate maternal health in rural areas.

As opposed to the authors' hypothesis there was no significant relationship between assessment of essential parameters of pregnant women at the first ANC visit and total number of visits. These results could partly be explained by lack of alternative of these women and the presence of high degree of ignorance which was manifested by high satisfaction in the circumstance of poor quality of ANC services. These findings suggest also that improvement of ANC may not necessarily improve attendance in this region.

Health care providers attributed substandard ANC to irregular supply of essential equipment and drugs, poor infrastructure for ANC and shortage of staff. The fact that $\mathrm{Hb}$ was estimated in only $37 \%$ of ANC visits despite $\mathrm{Hb}$ estimation machines being available in $64 \%$ of health facilities raise more questions on the performance, accountability, commitment of health care providers and supervision in the health sector. Our findings recommend more resources to ensure regular essential supplies, drugs and equipment, train more skilled staff and carry out supportive supervision in order to improve ANC services $[14,16]$.

\section{Limitations}

The statistical analysis assumed that all observations were independent. However, in a first level health facility (dispensary or health center) there are usually few health workers who perform ANC. These are likely to repeat mistakes or deliver good care on all mothers they attend in ANC. Thus, consultations by the same health worker may not necessarily be independent from each other, and even more so if some equipment is missing. Validity of ANC card data: it was assumed that all data in the ANC cards were true. However, some tests may have been done, but not recorded; some tests may have been recorded, but not done. It was not possible to crosscheck through the interview with mothers whether all these parameters were performed or not. The fact that satisfaction to ANC services is subjective, the results posed a potential limitation. Satisfaction can be influenced 
by a number of factors including knowledge on the required types of services and attitude of the individual clients. Based on these factors, clients might have expressed different levels of satisfaction even if they received similar services.

\section{Conclusions}

This article reflects a worrisome state of substandard antenatal care in rural Tanzania resulting from complex interacting factors including persistent lack of skilled human and material resources as well as irresponsive leadership in the health sector. Findings from this audit program suggest substantial adverse impact on maternal wellbeing resulting from poor quality of ANC. These results suggest urgent response from those in control of the health system to invest more resources in antenatal care to avert the situation and enhance maternal health in Tanzania.

\section{Abbreviations}

ANC: Antenatal care; Cl: Confidence intervals; SFDDH: Saint Francis designated district hospital.

\section{Competing interests}

The authors declare that they have no competing interests.

\section{Acknowledgments}

The authors would like to acknowledge the contribution of Tanzanian intern doctors and Dutch medical students who took part in data collection as well as in the audit team. They would like to thank the hospital administration and the district health authority for allowing this study to be conducted in their health facilities.

\section{Author details}

'Department of Obstetrics and Gynecology, Saint Francis Referral Hospital, Ifakara, Tanzania. ${ }^{2}$ Department of Medical Humanities, EMGO Institute for Health and Care Research, VU University Medical Centre, Amsterdam, The Netherlands. ${ }^{3}$ Department of Community Health, Muhimbili University of Health and Allied Sciences, Dar es Salaam, Tanzania. ${ }^{4}$ Department of Obstetrics, Leiden University Medical Centre, Leiden, The Netherlands.

\section{Authors' contributions}

$A S N, A B J, J P$ and JVR designed and took part in the audit process and data analysis. DPU contributed to writing of the manuscript. All authors read and approved the final manuscript.

Received: 8 January 2012 Accepted: 23 July 2012

Published: 23 July 2012

\section{References}

1. Osungbade K, Oginn S, Olumide A: Content of antenatal care services in secondary health care facilities in Nigeria: implication for quality of maternal health care. Int I Qual Health Care 2008, 20:346-351.

2. Lindmark G, Cnattingius S: The scientific basis of antenatal care. Acta Obstetricia et Gynaecologica Scandinavica 1991, 70:105-109.

3. Chan $\mathrm{KL}$, Kean $\mathrm{LH}$ : Routine antenatal management at the booking clinic. Curr Obstet Gynaecol 2004, 14:79-85.

4. Nyamtema AS, Urassa DP, van Roosmalen J: Maternal health interventions in resource limited countries: a systematic review of packages, impacts and factors for change. BMC Pregnancy Childbirth 2011, 11:30.

5. Simona Di M, Vittorio B, Gianfranco G, Daniela S: What is the effectiveness of antenatal care. Copenhagen: WHO Regional Office for Europe; http://www. euro.who.int/Document/E87997.pdf.

6. Ministry of Health \& Social Welfare: Focused Antenatal care, Malaria and Syphilis in Pregnancy. Orientation package for Service Providers. Dar es salaam, Tanzania: Reproductive and Child Health Section; 2002.
7. Villar J, Ba'aqeel H, Piaggio G, Lumbiganon P, Belizán JM, Farnot U, AlMazrou Y, Carroli G, Pinol A, Donner A, et al: WHO antenatal care randomized trial for the evaluation of a new model of routine antenatal care. Lancet 2001, 357:1551-1564.

8. Tanzania National Bureau of Statistics: Tanzania Demographic and Health Survey, 2004-2005. Dar es Salaam: Tanzania National Bureau of Statistics; 2005:131-138.

9. WHO: Operational Research on Reproductive Health. New Delhi: WHO Regional Office for South-East Asia; 2000.

10. The 2002 Tanzania population and housing census results. http://www. tanzania.go.tz/censusf.html.

11. Nyamtema AS, Bartsch-de Jong A, Urassa DP, van Roosmalen J: Using audit to enhance quality maternity care in resource limited countries: lessons learnt from rural Tanzania. BMC Pregnancy Childbirth 2011, 11:94.

12. UNICEF/WHO/UNFPA: Guidelines for monitoring the availability and use of obstetric services. New York: UNICEF; 1997.

13. Graneheim UH, Lundman B: Qualitative content analysis in nursing research: concepts, procedures and measures to achieve trustworthiness. Nurse Educ Today 2004, 24:105-112.

14. Zanconato G, Msolomba R, Guarenti L, Franchi M: Antenatal care in developing countries: The need for a tailored model. Semin Fetal Neonatal Med 2006, 11:15-20.

15. Acharya S: How effective is antenatal care to promote maternal and neonatal health? Int J Gynecol Obstet 1995, 50(Suppl. 2):535-542.

16. Urassa DP, Carlstedt A, Nystrom L, Massawe S, Lindmark G: Quality assessment of antenatal program for anaemia in rural Tanzania. Int J Qual Health Care 2002, 14:441-448.

17. Boller C, Wyss K, Mtasiwa D, Tanner M: Quality and comparison of antenatal care in public and private providers in the United Republic of Tanzania. Bull World Health Organ 2003, 81:116-122.

18. Malabika S, Gerhard S, Elin L, Sylvia K, Manuela De A, Florian N, Theodora M, Isaack L, Olaf M: Quality of antenatal care in rural southern Tanzania: a reality check. BMC Research Notes 2010, 3:209.

19. Mwaniki PK, Kabiru EW, Mbugua GG: Utilisation of antenatal and maternity services by mothers seeking child welfare services in Mbeere District, Eastern Province, Kenya. East Afr Med J 2002, 79:184-187.

20. Anya SE, Abba H, Lamin ES J: Antenatal care in The Gambia: Missed opportunity for information, education and communication. BMC Pregnancy Childbirth 2008, 8:9.

21. Department of State for Health and Social Welfare: Report on the national survey on maternal, perinatal, neonatal and infant mortality and contraceptive prevalence. Banjul: DoSH\&SW; 2002.

22. Mwifadhi M, Brigit O, Joanna Schellenberg A, Haws RA, Mushi AK, Hassan M, Marcel T, David S: The use of antenatal and postnatal care: perspectives and experiences of women and health care providers in rural southern Tanzania. BMC Pregnancy Childbirth 2009, 9:10.

doi:10.1186/1471-2393-12-70

Cite this article as: Nyamtema et al.: The quality of antenatal care in rural Tanzania: what is behind the number of visits?. BMC Pregnancy and Childbirth 2012 12:70.

\section{Submit your next manuscript to BioMed Central and take full advantage of:}

- Convenient online submission

- Thorough peer review

- No space constraints or color figure charges

- Immediate publication on acceptance

- Inclusion in PubMed, CAS, Scopus and Google Scholar

- Research which is freely available for redistribution 